\title{
Contextualizing Power Politics of Tamasha Art and Female Suffering in Dalit Autobiography
}

\section{Morve Roshan K.}

Center for Comparative Literature and Translation Studies, School of Language, Literature and Culture Studies, Central University of Gujarat, India

Volume 1, Number 2/2014

DOI:

Licensed:

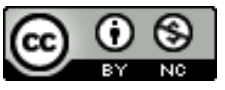

Source of Support: Nil

Conflict of Interest: None declared

Email for correspondence: morve_roshan@rediffmail.com

\begin{abstract}
"Tamasha" is a form of entertainment, which came in the 16 th century and transforms it into business and politics after the independence of India. It became a cultural part of the Kolhati community in Maharashtra. This paper has significant to define that the politics of Tamasha and female suffering through the twentieth century dalit autobiography Kishor Kale's Kolhatyach Por (1994). It will also discuss that his personal and painful experiences where he born and grown up in the misery environment. It needs to understand that how the dalit women becoming the victims of politics and how their family takes tragic and painful end. Therefore, this paper tries to make a link between the Tamasha dancers and the dalit experiences through the power politics. In the end, it comes to conclude that emergence of the dehumanized social conditions and ignorance of the dalit Kolhaty community. It demands for their right and the respect of the Tamasha art.
\end{abstract}

Key words: Kolhaty; Maharashta; tamasha; dancer; politics; Dalit autobiography

\section{INTRODUCTION}

'Tamasha' is a Persian word meaning is fun or entertainment. Other scholars suppose that diverse pieces of musical dance and dramatic entertainment to form tamasha something came in Maharashtra in the $16^{\text {th }}$ century, in the Mughal period. Some scholars have suggested that tamasha developed out of the decaying remnants of two forms of classical Sanskrit entertainment - the 'Prahsana' and the 'Bhana' (Brandon, 1993). The theatre forms of India like Tamasha, Jatra (popular folk-theater) and Bhavai, which are going to perform with the particular group of people in India. Especially, Tamasha is a popular in Maharashtra since the 16th century. 'The principal folk theatre form of Maharashtra State in Central India is Tamasha. It functioned as a bawdy, lascivious entertainment for the 
armies of Mogul and Maratha. In Maharashtra, Tamasha (as it is also known as Lok Natya or people's drama) was successfully used during and after the 1940s to spread the doctrine of Communism among the villagers. It is a bawdy form of popular theatre, distinguished by female artists. Who dance and sing. Although this form is still popular today also (Abrams, 1975; Richmond, 1973). Tamasha troupes are of two varieties: (i) Sangeet-baaris (song troupes) - which specialize in song-and-dance entertainments, and (ii) Dholki-baaris (folk drama troupes) - which includes dramatic presentations, called vags, as well as songs and dances. A Sangeet-baari is produced up, on the average, of five or six female dancers and singers, with some instrument players. The Dholki-Barrie takes, it is named from the cylindrical, two-sided drum, slung from the shoulders, which provides the most characteristic rhythms in Tamasha. Additional troupes were to be set up in remote villages' (Abrams, 1975). Tamasha is the traditional and business part of the Kolhaty. In Maharashtra, only Kolhaties have authority to perform the Tamasha; there are restrictions for other persons. They have a duty to live in the troupes and perform the dance village to village. In India communities has distributed the particular work has to do with the selected groups. There was the labor divided policy exist. As a Kolhati girl, her duty is to devote the life in dancing and singing. Here, we can see that after the independence time, Tamasha becomes more political, and a form of art has become a business.

\section{Dalits EXPeriences in the Dalit Autobiographies}

The Dalit literature movement first time began in Maharashtra 1960, in the form of poetry, fiction, and autobiographies. It is a significant genre of Indian literature. It led to dalit exploitation in the form of social-political as well as cultural way. It stressed on the oppressed marginal voice. 'This process was evident particularly in Maharashtra - a state that has always been prone to progressive. Also, because of the domineering presence of the Ambedekarite Ideology. Follows his ideology of permeated a sense of human dignity and rebelliousness against injustice into their thinking' (Bhongle, 2002). The values of autobiographies are definitely not a particular individual identity, but also carry a collective manner. The study of Dalit autobiography has helped to understand the pain of someone, there is no any kind of imaginary world, no anyway have chosen for to fictionalize. It is very simplistic and realistic way to know better the reality of the world. Because someone's experience cannot be a similar but when it enters into the majority, it increases the autobiography's value.

The Dalit literature used medium by dalit to reach the message of suffering. The world is unknown of this real fact of dalits life. The number of dalit writers has touched the issues of poverty, struggle for identity, marginality, and they become a victim of politics. 'Dalit autobiographies in Marathi came to be written during the day of the movement of Dalit literature itself. Daya Pawar wrote his autobiography - Baluta - (a reward for the Mahar community in Maharashtra in return to the various services offered to the high castes) when his poetry was widely appreciated. P.E. Sonkamble's Athwaniche Pakshi (Birds of Memories), then came out a spate of Dalit autobiographies - Mukkam Post Devache Gothne (At Post Devache Gothne) by Madhav Kondvilkar, Fanjar (A Thorny Bough) by Nanasaheb Zodge, Jina Amcha (Our Life) by Baby Kamble, and Udhwasta Vyayacha Mala (I want to be Ruined) by Mallika Dhasal. These autobiographies, narrating the experiences of caste. This feeling of being alienated is effectively illustrated by Laxman Mane in his autobiography entitled - Upara (An Outsider), by Laxman Gaikwad in Uchalya (A Lifter) and by Kishor Shantabai Kale in Kolhatyacha Por (Son of a Kolhati), and Sham Kumar Limbale's Akkarmashi 
(Being Illegitimately Born) narrates a unique story of being illegitimately born. Therefore, their relevance to the contemporary cultural context is highly corresponding' (Bhongle, 2002). These writers represented the real experience of brutality as well as unequal treatment by a man. 'Autobiographies have always been a popular form of writing because the experiences of an individual have perennial instructing values. Dalit autobiographies, however, have little to instruct; rather they explode myths about human values and dignity. They reveal that aspect of society, which in its blatant form of ugliness, speaks for the total disregard for the suffering humanity' (Bhongle, 2002). Kale's autobiography has a different characteristic because this is the autobiography has written by the Kolhati man. These community people are illiterate and unable to understand the politics of the upper class people.

So, Kale tries to touch this issue for addressing the painful message to the world.

\section{Power Politics and Female Suffering in Tamasha Art}

The entire Dalit literature tends to be autobiographical because the Dalit writer refuses to soar high with the wings of imagination. He prefers to write out of the authenticity of experience (Bhongle, 2002). To develop the appropriate political message, the party commissioned various writers to frame stories in Tamasha. The traditional form of theatre frequently employed by the Communist Party for its own propaganda campaigns in Maharashtra. One of the stories developed for the Ruling Congress was We Must Win This Time by Jagidish Khebudkar (Richmond, 1973). The other best example of dalit autobiography is Kishor Kale's dalit autobiography Kolhatyach Por (Son of a Kolhati) written in 1994. He is a Marathi dalit writer, social worker and a doctor. He died in an accident in 2007. He was the illegitimate son of Shantabai, who belongs from the Maharashtrian Kolhati community. His father does not agree to give him as his name. Therefore, he associates himself by his mother's identity. His writing deals with the contextual framework of male dominated society, politics and woman suffering in tamasha. This paper has an aim to represent the experiences by drawing with not only the story of the author, but also a story of all Maharashtrian Kolhaties. 'The most dominant feature of Tamasha in the twentieth century is it utilization for social and political propaganda' (Abrams, 1975). Kale's autobiography demonstrates that social-political effects in his life. Shantabai Kale abandoned to his son Kishore at a very little age and left him in the uncaring grandparent's house. It also reflects experiences with all of the tamasha dancers and the author's experience in educational life in this autobiography. The threegenerational story woven around Jiji (Kishor's grandmother), Shanta (Kishor's mother) and Kishor (author). The opening of the story starts with Jiji and childhood experience of the Kishor. Autobiography has ambition to show it's experience in society through language as like portraits the picture of his personal life and household. Kishor Kale unfolds a sad and shocking story of his childhood to adulthood with a rare simplicity and frankness, whether inspires the reader to never lose hope.

A society considers Tamasha is an art, a source of fun, but it has hidden an exploitation, and domination in Maharashtra folk Theater. Kolhati woman becomes figure of a prostitute, but author condemns to this view and said Kolhati women are not prostitutes. They are very honest, but the Panchayat (Village Council in India) was not given the permission for marriage. So, they keep illegal relations with the upper class men and as a result; they give birth to the child. By the culturally, based on Kolhati law - Kolhati girls have to go everywhere for performing dance and cannot marry with anyone. Kale has an 
aim to define the picture of women for the culturally they are suffering and the economic inequality they troubled more. Art becomes a part of business and profession, which rule over the girls. These girls are far from knowing the political acts of patriarchy. On the one hand, women are worker and the other hand; they are puppets in hand of landlords. Head of the family member, landlords, and the theater owner all these are responsible for dominating the voice of Kolhati women. They are depressing the women's freedom, and these women are becoming victims of political acts.

\section{THE Structure OF "TAMASHA"}

Anil Awachat (1980), writes, "the auditorium itself is a covered yard with rows of benches, flanked by two broad concrete platforms. The bench/desks are filled with people. One side of the stage sits an organ player at an old organ; on the other side, a tabla player with a drummer or dholki player below him. At the sound of a shrill whistle, half a dozen women appear on the stage wearing gaudy nine-yard saris of assorted colors, bright with plastic zari work. Strings of ankle bells around their ankles and glittering in costume jewelry. The elderly to the very young and an older woman begins singing, two young girls come to the stage front and begin to dance. Men in the audience began to hold out notes, which the girls came dancing around to claim. But the notes are not made too easy to get. The dancers must lean over the railing and the withholding patron until he is pleased enough, by the obscene bending, stretching and teasing, to part with the note. The girls danced to the front and returned the required change to the 'patrons.' The running to and fro became faster. The chase became hotter. A man from the audience walked up and stood by the other side of the stage. His clothes were torn and dirty. He held out a rupee note. A dancing girl danced her way to him. As he handed his rupee over, he whispered something to her. She went back, covered her head with the end of her saree, put a finger to her cheek and returned dancing and miming the actions of a shy maiden, throwing coy, sidelong glances at her patron. The man gave her another rupee and probably asked for a special song, for when she began that he went back to his seat" (Awachat, 1980). These are the structural background of the Tamasha Theater. The same bad experiences of dancer's like Shanta, Chandrakala and Kastur and all these women have the same experience in this autobiography. The main stock in trade of these women is their youth. And there are cases of talented women per- formers who have died as beggars. The theater owner does not give permission to go anywhere. Only Sunday they have authority to pass away. Kale has described the satirical way of the society towards Kolhati woman's life have a lack of freedom. Kale captures a movement to define dalit women suffered by upper class people. An upper class person makes a weapon as a caste to dominate. We have a history to see that the caste of the slaves played a crucial role in the kind services forced upon them. It emerges, therefore, that the sale of women of the lower castes was necessary for the later Peshwa state. In the $17^{\text {th }}$ century, the female slaves of the Peshwa state seemed to fall into two categories; the 'kunbinis' (bought for domestic and agricultural labor) and those bought for their sexual labor, either by individuals or for the dancing houses of the state. In Peshwa tradition, it was required to present gifts to these women. After the Peshwa this tradition, continue by the landlords. The power has come at the landlords's hand. They have relationships with the women, and when they gave birth to a child the land lords abandon the relationship and never come back to them. Such as sexually exploited women abused by the society. The society has given name 'prostitute' and abused them. 
The author defines power politics in Tamasha tradition, which is a business for Kolhati caste. All the same, this profession turns towards the tragic journey. It implies that women abused, suffered and degraded by male. We can determine in the autobiography Kondiba forced to his own daughter for the dance.

Kondiba used to tell mother to go to a party. But mother not ready to go because of she hates that atmosphere. She does not like to dance. Her aspiration was to become a teacher. Mother was crying and tells her pain to father Kondiba, because she got bad experiences in performing dance. When she performed a dance at that time suddenly one man holds her hand, and another incident in Manwat, one man was trying to elope her, but this plan was unsucceed because Chandrakala's brother had come, otherwise she will be a victim of his desire. But Kondiba did not hear anything because he has lusted for only money (Kale, 1994).

In Kondiba's family daughters are workers, merely not the sons. It is indicating that Kolhati men keep their women busy in dancing and singing for acquiring profits. The daughter of Kondiba's Kastura and Shanta dream to become teachers, but forcefully, they became a dancer at a very young age. It was because in Kolhati caste there was a rule for girls that they have to earn money and perform village to village. Kondiba forces for dance performing to Shanta. Shanta got many strange experiences in performing dance. Baby and Sushila in little age, they left school and turn to dance. Tamasha dancers always give light to the audience, but burnt themselves as a candle. The audiences enjoy this dance, but they are not aware of the dancer's condition. When women performed a dance, they have pain in the body. They lived apart from family. Man abuses and they do not have their own will to dance. They do it because their family forced them to act. Shanta's father who was always demanding money, which led her to dance. Kishor still gets to suffer when Shanta is married to Nana as he also dominates or beats her. Nana had been married to Radha. Thus, a woman becomes a victim of class, caste and patriarchy or power politics. One more incident is that Kusum leaves with Kamble (who is Mahar) so, Panchayat was not allowed to set aside for giving return in the Kolhati community. Hari (Kusum's brother) takes Sanju (Kusum's illicit son) and goes to Bombay for meeting Kusum, so Kolhati community banished to Harri and Kusum. In addition, people call to Ramdada is a criminal and a thief because of his daughter leaves with a Mahar man.

In this autobiography, the illicit relationship is a part of suffering women. The illegal relationship describes that the dominant policy of men. It is also gives birth to a dangerous disease like AIDS. Baby with Shivaji, Pawar, and Hambi Rao Patil. Sushila's relationships with Sopan Rao and Ramesh, Kustur's leaves with Pathan, and Shanta's with Dharurkar and Nagdeo Rao. In all cases, the society does not accept the relationships because they are Kohlaty. These men frauds with them after they hold open the relationship, left them, and never get back. When Shanta lived with Krishna Rao Wadkar, her life shifted to suffering. She suffered because of her husband's dominant nature, and he never takes care. It indicates that devaluation of women, subjectivity and passivity of women. Nana her husband always used to beat as well as always dominating. Often Shanta had been ill and disturbed. Even Shanta had to live apart from her own child for a long time as a society would not accept an illegitimate child and Nana was not ready to give permission to Kishor to live with him. One other incident was the burning Kastur no one knows why or who burnt her and the death of Chandrakala. No one recognizes the reason behind that. The number of cases was similar in the village. 


\section{PAIN IN THE BODY}

Like, Veena Das, Asad insists that the pain is not merely a "private experience" but a "public relationship", as Wittgenstein taught us long ago. Veena Das points to the Blue and Brown Books where Wittgenstein answers the question of how one's pain may reside in the body of another body (Aras, 2014)-

In order to see that it is conceivable that one person should have pain in another person's body, one must examine what sorts of facts we call criteria for a pain being in a certain place...Suppose I feel a pain which on the evidence of the pain alone, e.g. Which closed eyes, I should call a pain in my right hand. I do, so and looking around to perceive that I am touching my neighbor's hand....this would be pain felt in another's body (Aras, 2014)

Veena Das explains Wittgenstein to be using the estimation of a philosophical grammar to understand the pain. In this rendering, it is not that inexpressible something that marks an exit from one's existence in language. 'I was learning in $10^{\text {th }}$ standard. I missed my mother a lot. She is sick, who will serve her food? Who will take care of her? And did someone take her to the hospital? These thoughts were making me mad' (Kale, 1994). In either case, it is not a referential statement that is pointing to an inner object. Kishor always worried about his mother. Shanta suffered, and her annoyance is felt in Kishor's body. Family constantly degrades him. In college life, Kishor hurts by friends an account of his mother is a dancer. Everyone never cared about him, bitten him and hurt him and at young age he great a deal.

When Tamasha emerged as a popularly accepted form (about the time of the Maratha warrior, Shivaji the Great, in the Seventeenth century), the entertainment value became more pronounced, but so did the message carrying potential. In Shivaji's time, the messages shifted from themes of devotion and morality to the more secular and emotionally appealing ones of bravery, nationalism, and militarism. In the process, the poet-saints gave way to the new breed of people's poets, or Shahirs, who roamed the Deccan singing stirring Povadas, or ballads, in praise of the brave Shivaji. The first issues of the twentieth century, as reflected in Tamasha, included the prevailing caste system, illiteracy, outmoded superstitions, and the oppression of women (Abrams, 1975). We require seeing the twentieth century condition of tamasha and reality as well as history continuation of man dominated policy. We can see power politics has taken a role in tamasha; women doubly suffered - (i) As a Dalit, and (ii) as a Woman. Author opens up the sociological and political issues. He dissociated sexual violence from public practices of the power structure. He assumed the prevalence of caste habits and his judgment on the idea of an inequality in mind at work. Lower caste women have long suffered sexual violation as caste exploitation and forced sexual labor. Desire of rape is caste violence. Women are sexually abused, murdered and beaten by landlords. The routine of cases occurred in villages like Chandrakala and Kastur. Landlords give some money and often provide them shelter to stay, properties, money, and through this they maintain their relationship with dancers. Later on some days, abandon the relation and never get back to them. The author has proposed to define the women's political history brings inequality. The twenty-first century world, bar dancers, the tamasha dancers and women are becoming the victims of serious diseases like AIDS so, Kale has an intention to aware them and show that he touches to the issues, which are alive today also. 


\section{CONCLUSION}

This paper attempts to understand the Marathi dalit autobiography and to see how the passivity or questioning of silence in women's subjectivity. This paper realizes the texts to put them in the modernity of tamasha tradition, and female suffering with politics or societal consequences. It also traces the history of tamasha related to politics as well as the traditional continuation of it. The author attempts to seem at the journey of tamasha dancers and their tensions as they/their family are suffering in this world. These papers not only demands of the female right, but also respect from the society and to aware the value of Tamasha art.

\section{BIBLIOGRAPHY}

Abrams, Tevia. (October, 1975). "Folk Theatre in Maharashtrian Social Development Programs". Educational Theatre Journal, 27(3), 395-407. Popular Theatre. The Johns Hopkins University Press website: http://www.jstor.org/stable/3206466. Accessed: 11/03/2014. 05:34

Aras, Ramazan. (2014). The Formation of Kurdishness in Turkey: Political Violence, Fear and Pain. Oxon: Routledge.

Awachat, Anil. (1980, July 26). "Tamasha: Folk Art as Business". Economic and Political Weekly. 15(30), 1257-1259 website: http://www.jstor.org/stable/4368892. Accessed: 27/11/2012. 06:21.

Bhongle, Rangrao. (2002, July-August) "Dalit Autobiographies: An Unknown Facet of Social Reality". Indian Literature, 46(4), 158-160. Sahitya Akademi. website: http://www.jstor.org/stable/23345666. Accessed: 11/03/2014 06:16.

Brandon, James R. (1993). The Cambridge Guide to Asian Theatre. (Ed.). United Kingdom, UK: Cambridge Press.

Daedalus". Social Suffering, 125(1), 67-91. The MIT Press of American Academy of Arts \& Sciences. website: http://www.jstor.org/stable/20027354. Accessed: 01/12/2012. 01:56

Das, Veena. (1996, Winter). "Language and Body: Transactions in the Construction of Pain

Kale, Kishor. (1994). Kolhatyach Por. India Printing House, Mumbai, India: Granthali.

Rao, Anupama. (2010). The Caste Question. New Delhi, India: The University of California Press.

Rege, Sharmila. (2002, June 22-28). "Popular Culture". Economic and Political Weekly, 37(25) 2374. website: http://www.jstor.org/stable/4412250. Accessed: 27/11/2012. 06:31.

Richmond, Farley. (October, 1973). "The Political Role of Theatre in India". Educational Theatre Journal, 25(3), 318-334. The Johns Hopkins University Press. website: http://www/jstor.org/stable/3205692. Accessed: 11/03/2014 06:09.

Wittgenstein, Ludwig. (1960). The Blue and Brown Books. (2nd ed.). New York, NY: Harper Torchbooks.

This article is is licensed under a Creative Commons AttributionNonCommercial 4.0 International License. Attribution-NonCommercial (CC BYNC) license lets others remix, tweak, and build upon work non-commercially, and although the new works must also acknowledge \& be non-commercial.

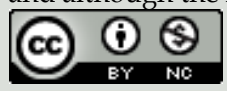

How to Cite: Roshan KM. 2014. Contextualizing Power Politics of Tamasha Art and Female Suffering in Dalit Autobiography Asian Journal of Humanity, Art and Literature, 1, 77-83. 


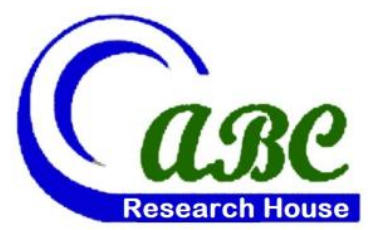

- Off Pantai Dalam, Kuala Lampur, Malaysia

- Road \# 4, Shyamoli, Dhaka-1207, Bangladesh

- 3900 Woodhue Place, Alexandria, VA 22309, USA

www.abcreorg.weebly.com / www.abcjournals.net

Asian Business Consortium (ABC) is a multi-disciplinary research, training, publishing, digital library supporting and service house. Though founded in 2010 as the Business and Computing organization of Asia, it was reconstituted as the ABC in 2011. It has been working for creating and nurturing talents in USA, Malaysia and Bangladesh since its inception. The objectives of consortium are solely centered round the welfare and humane attitude of the founders who enthusiastically took up this noble cause and materialized it with a view to promote research and educational activities for the encouragement of scholars to develop their knowledge, to publish their analysis oriented scientific researches in international Journals, books, the task of organizing workshops, seminars, conferences, training, personality development programs and allied services.

In addition to research activities, $A B C$ provides a good number of scholarships to the poor and meritorious students at various levels of education throughout the world. It plays an important role in the field of research by funding research projects and publishing the research papers. This consortium will unquestionably become the mouth-piece of the dark horses and unacknowledged scholar whose endowed and commendable contributions shall be provided an outlet keeping in mind the greater good of the larger society of the world.

$\mathrm{ABC}$ runs the following international referred journals for creating a platform to share the thoughts of professionals, scholars and academicians throughout the world.

\section{ABC Publications (ABC Journals)}

- Asian Accounting and Auditing Advancement (4A Journal)

- Asian Business Review (ABR)

- Asian Journal of Applied Sciences and Engineering (AJASE)

- Global Disclosure of Economics and Business (GDEB)

- $\quad$ ABC Journal of Advanced Research (ABC-JAR)

- International Journal of Reciprocal Symmetry and Theoretical Physics (IJRSTP)

- American Journal of Trade and Policy (AJTP)

- Asian Journal of Humanity, Art and Literature (AJHAL)

- Malaysian Journal of Medical and Biological Research (MJMBR)

- $\quad$ Asia Pacific Journal of Energy and Environment (APJEE)

- $\quad$ Engineering International (EI)

- $\quad$ ABC Research Alert (Online)

Each journal home page provides specific information for potential authors and subscribers. Open access policy, the quick review process, rich editorial boards and quality publications have already made $A B C$ Journals unique. ABC Journals are published under the direct supervisions of renowned academicians of the world.

Collaboration in Conference: $\mathrm{ABC}$ considers high-quality conference papers for publication. Please contact us for detailed information.

Collaboration in Publishing: If you like to start writing a book, propose a new journal or advertise in $\mathrm{ABC}$ journals, please feel free to contact us. 